
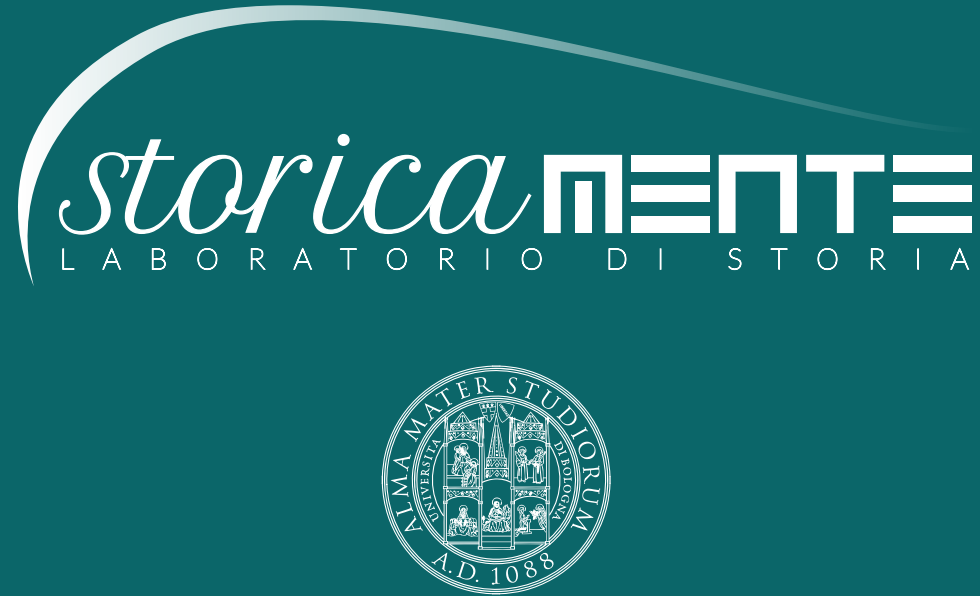

ALMA MATER STUDIORUM

Università di Bologna

Dipartimento di Storia Culture Civiltà

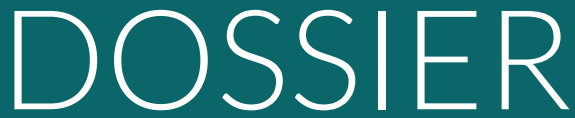

IMPERI: POLITICHE ED EREDITÀ NEL

"LUNGO NOVECENTO"

(ITALIA, PORTOGALLO, SPAGNA) 


\section{STORICAMENTE.ORG}

\section{Laboratorio di Storia}

Ferran Archilés Cardona

¿Una cultura imperial? Africanismo e identidad nacional española en el final del siglo XIX

Numero 12 - 2016

ISSN: $1825-411 \mathrm{X}$

Art. 5

pp. 1-25

DOI: $10.12977 /$ stor621

Editore: BraDypUS

Data di pubblicazione: 10/07/2016

Dossier: Imperialismi e retaggi postcoloniali in Italia, Portogallo, Spagna, a cura di Matteo Pasetti 


\title{
¿Una cultura imperial? Africanismo e identidad nacional española en el final del siglo XIX
}

\author{
FERRAN ARCHILÉS CARDONA \\ Univ. València, Departamento de Historia \\ Contemporánea, Facultad de Geografía e Historia
}

In the context of acute perception of a national identity crisis the aim of an African empire was conceived as a solution. In the era of European imperialism it became a key to national regeneration. This article offers an analytical perspective on the importance that the "Africanismo" achieved at the end of XIXth century in Spain, from the perspective of comparative history. Although the Spanish case cannot simply be classified as other European imperialism, it has been excessively exaggerated their uniqueness or anomaly. This article is based on a reading of the literature as well as in the use of certain sources, mainly intellectual discourses, to raise a new interpretive perspective.

\section{Premisa}

Entre las muchas ausencias o desapariciones de la historia de España de los relatos generales sobre la historia europea o global, la del imperialismo africanista español es un elemento que ha pasado especialmente desapercibido. Como ha señalado Stephen Jacobsen la historiografía ha dedicado mucha más atención a la construcción del imperio 
español que a su declive, especialmente en el caso del imperio español en el continente americano [Jacobsen 2012]. Por su parte, la presencia española en África ha tendido a ser minimizada, reducida a ocupar un lugar menor, cuando no anecdótico.

Sin embargo, España, incluso después de 1898 tras la independencia de Cuba, Puerto Rico y las Filipinas, mantuvo una vocación colonial. La vocación de un Imperio que finalmente se trasladó hacia África, hacia la necesidad (pues así fue percibida por importantes sectores de la cultura y la política desde los años ochenta) de buscar un nuevo imperio en el norte de África, en Marruecos's. En el contexto de la aguda percepción de una crisis de identidad nacional (en breve una crisis poscolonial), el imperio africano fue concebido como una solución. En la era del imperialismo europeo pasó a ser una de las claves para la regeneración nacional.

Este artículo pretende ofrecer una perspectiva analítica sobre la importancia que el discurso africanista tuvo en el fin de siglo español, desde una perspectiva de historia comparada. Si bien el caso español no puede equipararse sin más a otros imperialismos europeos, se ha exagerado en exceso su singularidad o anomalía. Este artículo se basa en una relectura de la bibliografía existente así como en el uso de ciertas fuentes, básicamente discursos intelectuales, para plantear una nueva perspectiva interpretativa.

\section{El imperio español en contexto}

Es bien sabido que por falta de medios el Estado español tuvo que renunciar a proyectos imperialistas de gran alcance. Sin duda la acción colonial española en África se abordó con recursos limitados y sus re-

1 Para una primera versión del presente argumento véase: Archilés 2013.

2 La síntesis más reciente: Akmir 2009. 
sultados (como sucedió desde un punto de vista económico) fueron igualmente limitados, algo que tal vez no sea una singularidad española, si lo comparamos con, por ejemplo, el caso italiano. Además no fue una acción especialmente tardía, pues la expansión africana de España en el siglo XIX no estuvo cronológicamente demasiado alejada de la que emprendieron Italia o Alemania [Labanca 2007, Conrad 2011]. Ciertamente, cabe señalar que desde el Estado se abordó con notables limitaciones el desarrollo de las vías de nacionalización asociadas a un proyecto imperialista de gran alcance. No hubo un «imperialismo popular» aunque ello no significa que no hubiese estallidos en este sentido . En todo caso, es todavía poco lo que sabemos sobre la presencia del imperio en la cultura popular española. A pesar de las enormes diferencias de magnitud y naturaleza entre los diversos proyectos imperialistas europeos, la exploración de la difusión popular se está convirtiendo en una línea fructífera de trabajo para otros países como Bélgica, Holanda o Italia, mientras que el caso español ha quedado al margen, así como el portugués [MacKenzie 2011]. De hecho la ausencia del caso español en el estudio sobre el imperialismo es casi general, desde luego en lo que afecta a África ${ }^{4}$.

Giuseppe Maria Finaldi, ha planteado, respecto a los proyectos africanistas italianos, si existió una "cultura del colonialismo» [Finaldi 2009]. Podemos plantearnos la misma cuestión: ¿Existió una cultura del colonialismo en España? A la hora de trazar cualquier respuesta, convendría tener en cuenta que el grado real de difusión de los proyectos imperialistas es objeto de discusión incluso en el caso británico, donde aparen-

3 No se puede hablar en el caso español de un "imperialismo social” a la manera que fue planteado por H. U. Wehler. Una útil reflexión historiográfica: Jefferies 2008, 26-50. Sin embargo, algo de ello estaba en el horizonte de los regeneracionistas españoles, que cifraban en la ocupación africana la solución al atraso económico y social de España, y en definitiva de la pobreza.

4 Un ejemplo reciente: Lorin, Taraud 2013.

5 Para el caso alemán, véase: Short 2012. Una visión de conjunto en Sibeud 2013, 335-376. 
temente se daba por descontada [Porter 2004, Thomposn 2005]. Es bien cierto que en España los proyectos coloniales, cuando implicaron aventuras bélicas, despertaron frecuentemente una notable animadversión como sucedió con los acontecimientos que culminaron en la Semana Trágica de Barcelona de 1909. Pero tampoco conviene olvidar que, de manera reiterada, diferentes conflictos de naturaleza imperialista contaron con un grado de popularidad no desdeñable (como fue ya el caso de la guerra de Marruecos en 1859 [García Balañá 2002]) o una identificación con los valores de la nación amenazada que es difícil no calificar de nacionalista7. Sucedió con el conflicto de 1885 con Alemania por las Islas Carolinas [Elizalde 1992], y también, desde luego, con la guerra hispano-cubana, especialmente cuando se involucraron los Estados Unidos, momento en que se produjo una auténtica explosión de nacionalismo español casi en todos los ámbitos del espectro político (con la excepción de los republicanos federalistas y ciertos sectores del incipiente nacionalismo vasco). Tampoco habría que olvidar que, aunque pasajero, el ardor patriótico estalló tras el desastre de Annual [La porte 1996, Balfour 2002, 171]. Lo mismo sucedió con la llamada guerra de Melilla de 1893, probablemente más popular de lo que se acostumbra a plantear. Todo ello sin cuestionar que, en efecto, es muy difícil hablar de una opinión pública unida al respecto ${ }^{8}$. El colonialismo español del periodo de la Restauración borbónica (que se inicia en 1875) se concentró en cuatro ámbitos: las colonias del continente americano; las islas Filipinas y áreas afines en Asia (como las islas Carolinas.); Marruecos y Sáhara y la costa de Guinea en Africa. Hasta 1898, el ámbito americano continuó siendo el eje central junto con

6 Véase el debate posterior: Porter 2008, MacKenzie 2008.

7 Muestras de un «imperialismo popular» respecto de Cuba, al menos hasta la Primera Guerra Cubana (1868-1878) en García Balañá 2012.

8 Un interesante estudio de caso: Gajate Bajo 2012. 
las islas Filipinas [Fradera 2006] ${ }^{9}$. Finalmente las esperanzas de futuro se concentraron en el ámbito marroquí, cuajando a partir de la conferencia de Algeciras en 1906 (que abriría las puertas al Protectorado en 1912 [González Alcantud, Martín Corrales 2007]). Pero lo cierto es que en las décadas de los ochenta y noventa del siglo XIX, los proyectos coloniales para Cuba, Filipinas o Guinea, se solapan unos a otros y conformaron un contexto de reinvención colonial española del cual el proyecto africanista acabó siendo la pieza final.

En 1859, la guerra de Marruecos evidenció la voluntad de expansión en el Norte de África y también en el Golfo de Guinea. Se trataba, en principio, de un asunto de prestigio militar más que de anexión territorial. Pero a partir de los años ochenta el norte de África se convirtió en el ámbito compensatorio de las ambiciones colonialistas españolas, el marco de un auténtico espejismo colonial. Ocupación militar, expansión comercial y misión civilizadora se aunaron en la política y el imaginario español finisecular [Morales Lezcano 2002].

El presente trabajo tratará de mostrar que el peso de una deriva imperialista centrada en Marruecos desde finales del siglo XIX, fue clave y aunque parcialmente fallido y de alcance limitado (y marcado por especificidades tanto como lo estuvieron otros casos) no fue tan anómalo respecto a su contexto europeo: no por lo que respecta a su dimensión cultural y su contribución al imaginario de la identidad nacional española. Tampoco en sus planteamientos y representaciones «civilizatorias».

Mi objetivo no es, por tanto, volver al estudio del alcance de la expansión territorial o económica del imperialismo español en África, sino centrarme en la representación del Imperio en la cultura nacional española. Incidiré por lo tanto en los repertorios posibles del imperio tal y como era deseado «en casa», en la metrópolis. Todo proyecto imperialista conllevó unas prácticas discursivas y la elaboración de unas «fantasías 
coloniales», con los miedos y ansiedades que el imaginario imperial representaba [Cooper, Stoler 2007]. Como hemos analizado en otro lugar, no por casualidad también en el caso español la representación de género llegó a ocupar un espacio central de las fantasías coloniales [Archilés 2012].

En el seno de los imaginarios imperiales (y sus ansiedades a cuestas) se hallaba una autorrepresentación de la identidad nacional, como parte de la definición cultural de la "comunidad imaginada». Independientemente del alcance real y de las limitaciones territoriales conseguidas, el imaginario imperial fue producido desde la metrópolis y para la metrópolis, en el caso español como en cualquier otro. Ello no significa negar el proceso de negociación e intercambio entre el centro y sus colonias. Al contrario, pero en todo caso es imprescindible afirmar que cualquier representación del imaginario imperial tuvo una repercusión en la metrópolis [Eley 2010].

En el caso español, este imaginario fue central en los ámbitos culturales e intelectuales generados des de la sociedad civil, aunque no hubo un rumbo preciso marcado por el Estado. Fue un imaginario producido en la metrópolis, pues el desarrollo de élites coloniales asociadas al proyecto imperialista español parece haber sido relativamente débil, así como sus logros culturales, al menos antes del Protectorado. Pero ello no disminuye la fuerza de la imaginación en la metrópolis, pues al contrario refuerza su a veces desesperado y obsesivo deseo imperial. No por casualidad el «Regeneracionismo» (esto es, la versión española de los discursos palingenésicos del fin de siglo europeo) fue profundamente africanista desde sus orígenes y la herencia (ya sin Joaquín Costa) se trasladó al menos hasta la primera década del siglo XX.

Lo cierto es que sorprende la desatención de estas dimensiones en los estudios sobre la construcción de la identidad nacional. Si bien disponemos de buenos estudios sobre los proyectos imperialistas y su lectura política, faltan por incorporar los miles de textos, un auténtico océano de papel impreso, que a través de libros de viajes, discursos científicos, 
artículos periodísticos, novelas, ensayos, además de otras manifestaciones artísticas, se ocuparon de Marruecos [Martín Corrales 2002, Gil Grimau 1988].

Pero el Imperio y el imperialismo, no han tenido cabida en el seno de la gran narrativa sobre el nacionalismo español y la identidad nacional y su ausencia en la bibliografía es casi absoluta ${ }^{10}$. Tal vez ello se deba a que estas grandes narrativas han estado centradas en la discusión sobre la fortaleza o debilidad de la nacionalización española contemporánea. En mi opinión, esta narrativa, le debe mucho, en su recuento de fracasos o lamentos, a una herencia un tanto invisible pero constante del propio planteamiento finisecular decimonónico [Archilés 2011]. En este sentido, uno de los «fracasos» más clamorosos y uno de los objetos de disputa más amargos (especialmente en las primeras décadas del siglo $\mathrm{XX)}$ habría sido la aventura africanista. Pero cabe insistir en que esta narrativa de las debilidades y fracasos es fruto en su origen, en gran medida, de una exageración nacionalista, de un lamento surgido en el seno del discurso de un nacionalismo español que fundamentó sus demandas y pretensiones, que conjugó sus ansiedades, en la acerba critica de insuficiencias. Irónicamente, este discurso sobre la nación procede, precisamente, de la versión regeneracionista y sus herencias en las que un acendrado imperialismo era la cifra para la superación de la decadencia y los males de la patria.

Pero además esta ansiedad de un país en estado crítico y la respuesta en demanda de un imperio no debe llevar a la conclusión de que el caso español fue una excepción. Antes bien, cabe situarlo en el contexto de una verdadera "cultura de la derrota» [Schivelbusch 2001]. Por definición, el imperialismo de entresiglos conllevaba una dimensión de competición entre naciones (entre Estados). En dimensión comparada, encontraremos esta insistente ansiedad por no quedar atrás en Francia 
[Hill 2008]; también en el caso alemán, como ha insistido Sebastian Conrad, donde la preocupación por la degeneración y crisis nacional fue clave en el desarrollo del proyecto imperial [Conrad 2010]. Y, lo que es especialmente relevante para la comparación con España, fue también en definitiva, el caso italiano, tras Adua, y el portugués tras el ultimátum británico de 1890, precisamente vinculados a la expansión africana [Pinto Coelho 1996, Andrade 2006]. En el caso de las naciones «latinas», el argumento de su decadencia a partir de la derrota francesa en 1871 fue de extrema importancia en los círculos intelectuales y políticos propios" ${ }^{1 .}$ Pero fue importante también y no en menor medida para su proyección - la creación de imaginarios y estereotipos - en la escena de la política internacional [Sluga 2006].

Pero además, por sorprendente que pueda parecer, habida cuenta de la magnitud de sus dimensiones efectivas, este fue también el caso británico. La sensación de un mundo que se estaba encogiendo y la pérdida de espacios, generó constantes debates para recuperar la nación de sus dificultades a través del Imperio [Bell 2007]. Una sensación que llegó a ser aguda especialmente a partir de la crisis abierta desde 1880 . De hecho cabe preguntarse si realmente el imperio Británico llegó a estar libre de ansiedades en algún momento.

No se trata, sin embargo, de negar las especificidades del caso español para subsumirlo en un "modelo» exitoso, entre otras cosas porque nunca existió un modelo único. Mi objetivo es discutir la idea de fondo de la anomalía del imperialismo africanista en lo que respecta a su contribución al imaginario nacional español (y sus límites).

Lamentablemente, casi todos los campos de estudio (de la literatura de viajes, al arabismo académico, de los relatos científicos a los estudios antropológicos, la pintura o la novela) se han analizado por separado, inconexos. Esta fragmentación, sin embargo, debilita la fuerza global

11 Para el caso español, véase: Aubert 2006. Para una interpretación general, véase: Frétigné, Jankowiak, 2008. 
que supone el conjunto, la fuerza del imaginario imperial. Finalmente, si bien ha podido llegar a reconocerse parcialmente su relación con el imperialismo (o con el orientalismo) no sucede lo mismo con la construcción de los imaginarios del nacionalismo español, donde su ausencia en la bibliografía es casi total.

La pauta para abordar el estudio de la contribución del imperialismo y sus discursos al imaginario de la identidad nacional la han marcado en gran medida los estudios sobre el Imperio Británico. La relación del mismo con la construcción de la identidad nacional, especialmente la matriz inglesa, se ha convertido desde hace años en un terreno clave para la comprensión de la identidad en las islas y su crisis posterior [Gikandi 1993]. De hecho, han resultado especialmente interesantes las perspectivas abiertas por el estudio de la presencia de la cultura imperial en la propia metrópolis [Hall, Rose 2006].

Lejos de tratarse de una especificidad británica, la importancia del imperialismo para la construcción de la identidad nacional, se ha abierto camino en el estudio de otros casos, singularmente en el estudio del caso francés. El periodo de la denominada «república colonial»o «imperial» [Bancel, Blanchard, Vergés 2003, Le Cour 2009], esto es la Tercera República aparece como momento decisivo. La misión civilizadora asumida por el imperialismo francés, ha sido estudiada en relación no sólo con las colonias sino con el relato legitimador de la nación [Constantini 2008, Baycroft 2004]. Todo ello ha ido dibujando en la última década, una reconsideración del imperialismo francés, donde la dimensión cultural y de la representación del colonizado en la cultura metropolitana, ha pasado a ocupar un lugar central [Aldrich 2006]. La revisión de algunas asunciones sobre la tensa y ambivalente noción de ciudadanía en el marco imperial, parece estar dando paso a un renovado relato de la construcción de la identidad nacional francesa [Thiesse 2010, 165-174, Coquery-Vidrovitch 2009]. 


\section{Una vocación imperial no tan singular}

En el marco de la Restauración, a la tradición colonial de época moderna se añadió la reformulación de la idea de la «Hispanidad». Este fue siempre un discurso contradictorio y con lecturas diversas, pero con un fondo común de naturaleza lingüístico-cultural y articulado en un sentido «racial», además [Marcilhacy 2010]. En torno a la crisis colonial finisecular se fraguó una renovada retórica de la hispanidad, que no era ajena en absoluto al contexto de crisis identitaria y ansiedad imperial en España ${ }^{12}$.

La dimensión «espiritual» y cultural era clave (como lo sería para el africanismo, desdoblado en misión civilizadora). Seguía presentando a España como un país que podía (y debía) hacer grandes cosas [Blanco 2012]. Por ello pudo servir de puente con el africanismo ${ }^{13}$ (casi literalmente en figuras tan destacadas como las de Rafael María de Labra, por ejemplo [Domingo Acebrón 2006]). Como señalara el escritor y convencido africanista Isaac Muñoz: «El Mogreb debe ser para España como una nueva América, a la que apliquemos viejas y sabias experiencias $(. .$.$) ¡Se convencerá alguna vez esta España inerte y rígida de que$ su futuro es el futuro africano? $\aleph^{*}$.

Si los discursos en torno a la Hispanidad acabaran finalmente por ser tras 1898 (aunque no por voluntad propia) ya sólo una forma de colonialismo retórico, el discurso africanista apuntaba hacia el deseado colonialismo "práctico". Pero el sentido de fondo, era el mismo que latía en las palabras de 1882 del arquitecto del régimen español de la restauración, Antonio Cánovas, en el Ateneo de Madrid (en un discurso

\footnotetext{
12 Esta redescubierta «Hispanidad» no fue ajena al magma regeneracionista, véase: Mainer 1988. Sobre el impacto en la historiografía americana véase: Schmidt-Nowara, 2006.

13 Aunque ello podía suponer un cierto lastre, motivado por la «leyenda negra» de la dominación americana. Véase una cerrada defensa de que los españoles pueden ser no solo «conquistadores» sino también «colonizadores»: Becker 1913.
}

14 Muñoz 1913, 45. 
dedicado significativamente a la definición de la idea de nación), cuando señalaba: "Mándanos el deber nuestro, visiblemente que entremos en el número de las naciones expansivas, absorbentes, que sobre sí han tomado el empeño de llevar a término la ardua empresa de civilizar el mundo entero: y para comprender por qué nos lo manda, sí que fuera bueno recordar sin tregua la honra, no extinta aun que heredamos de nuestros padres» [Canovas, 1883] ${ }^{15}$. La historia por tanto, actuaba como fundamento de la vocación colonial, una idea que encontraremos en casi todos los autores restauracionistas [De Reparaz 1907, 9-42] ${ }^{16}$. En realidad, todo ello se insertaba en el convencimiento profundo, como desarrolló el colonialismo francés, de que cada pueblo tenía un "genio propio» al que debía atenerse en la acción colonial [Reynaud-Paligot 2006, 228].

La década de los años ochenta fue decididamente clave. Ante el ingente volumen de materiales no cabe sino hablar de una verdadera obsesión por parte del mundo intelectual a favor de la presencia de España en África, en Marruecos. Algunos de los más importantes nombres del ámbito intelectual español participaron, desde Joaquín Costa a médicos, botánicos, geólogos o antropólogos que fueron también los grandes protagonistas. Es difícil evitar pensar que se ha minusvalorado esta producción científica, equiparable (en su naturaleza, no en su resultado) a las actividades de las potencias imperiales europeas. Con todo, en la España del cambio de siglo (de manera similar a Italia) el desarrollo de las «ciencias coloniales» y su profesionalización se realizó de una manera más dubitativa que, por ejemplo, en la Francia de la Tercera República [Singarevélou 2011] aunque ello no disminuye la importancia de su contribución.

Fue decisivo el papel jugado por las Sociedades Geográficas, con la de

\section{Cánovas 1883, 131.}

16 Para Gonzalo De Reparaz España era, en realidad, la precursora y maestra de las modernas naciones imperiales. 
Madrid fundada en 1876 a la cabeza [Rodríguez Estebán 1996, Nogué, Villanova 1999]. En 1883, se fundó la Sociedad Africanista y Colonial, cuya función es completamente comparable a las sociedades que se estaban fundando en Europa [Pedraz 2000]. En realidad, la cronología de estas sociedades geográficas y coloniales no muestra un desfase importante respecto de Europa, a los casos inglés y francés [Lejeune 1993], ni tampoco italiano - donde la derrota de Adua fue un impulso notable - [Monina 2002, Natili 2008].

Corresponde a Joaquín Costa la función de impulsor del moderno africanismo, al que dedicó notables esfuerzos organizativos (al menos hasta su desencanto a finales de la década). En 1883, ante el congreso español de Geografía comercial y mercantil, Costa afirmaba: «iLa raza española! yo tengo una fe ciega en sus destinos, yo la creo llamada a permanecer en el planeta, cuando tantas otras habrán ido desapareciendo; y otra vez esta convicción me mueve igualmente a recomendar a España la colonización». Para Costa, la acción imperial serviría para contrarrestar la herencia negativa (aunque preñada de posibilidades) del «carácter nacional» español [Costa 1883, 59, 75].

Al año siguiente Costa, ante la Sociedad Española de Africanistas, concretaba en Marruecos el ámbito preferente de la acción colonial española. La "regeneración» de Marruecos debía ser obra de España, su misión ${ }^{17}$. Desplegó una imaginativa argumentación, histórica, geográfica y antropológica que postulaba la proximidad entre la población española y la de Marruecos, debido a «algún parentesco étnico». Para Costa, «durante la Edad media fue Marruecos el mediador por cuyo conducto vino a España la civilización de Oriente; en la Edad Moderna, España ha de ser el mediador por cuyo conducto penetre en Marruecos la Civilización europea» [Costa 1884, 52-53]. La tarea civilizadora, por tanto, era la clave.

Mención aparte merece la idea del "parentesco», la idea de la proxi- 
midad, incluso «racial» entre España y Marruecos argumentada, eso sí, para justificar la inevitable relación entre unos y otros (su «hermandad» [Mateo Dieste 2003]), y la primacía española frente a otras potencias europeas, un argumento destinado a perdurar en parte del africanismo español. ¿Fue esta una peculiaridad del caso español? Y si lo fue ¿en qué modificó la naturaleza de la acción imperial española?

La genealogía del origen africano de los íberos fue trazada ya antes de Costa, por autores como Francisco Tubino o Manuel Sales Ferré. Pero en realidad, se trataría de reelaboraciones de algunas ideas defendidas por el francés Bory de Saint-Vincent, que a inicios del siglo XIX, tras la ocupación de Argelia por Francia, estableció una identidad entre guanches, bereberes, íberos y celtas, al servicio de la implantación de la civilización promovida desde Francia ${ }^{18}$. Para Carlos Cañete, la introducción en España del paradigma africanista sería el «resultado de la apropiación del discurso antropológico asimilacionista», de suerte que el intervencionismo «civilizador» o el hermanamiento serían la palanca para desarrollo y progreso de ambos territorios [Cañete 2009, 307].

A partir de los años noventa, llegó a teorizarse una raza «libio-iberica» por parte del antropólogo Manuel Antón y Ferrándiz, primer catedrático en España de la disciplina y probablemente el autor de una obra más coherente desde el punto de vista del alcance colonial ${ }^{19}$.

¿Hasta qué punto limitó ello este tipo de argumentos el sentido de alteridad frente al «otro» colonial o la voluntad de subordinación del mismo? En mi opinión bastante menos de lo que podría parecer. De entrada porque el propio Antón y Ferrándiz señalaba que independientemente de la similitud de fondo, el desarrollo histórico y la religión habían hundido Marruecos (lo que a su vez, por tanto, legitimaba la

18 En Portugal los historiadores Oliveira Martins y Teófilo Braga defendieron la identidad entre los íberos y los bereberes. Véase: Sobral 2004.

19 Antón Ferrándiz 1895, 31-39. Ya con trabajo de campo volvió al tema en Anton Ferrándiz 1910. Véase asimismo: Goode 2009, 37-96. 
acción colonial) ${ }^{20}$. En 1910, Idelfonso Yánez en un texto dirigido a los niños españoles de las escuelas africanas se mostraba partidario de las tesis que situaban los inciertos orígenes de la población marroquí como "pertenecientas a la raza libio ibérica, haciéndola así hijos de la misma rama genealógica que nosotros». Pero a partir de ahí afirmaba que a pesar de todos los contactos positivos con otras culturas los moros «no han perdido ni un ápice de su recelo primitivo y ni siquiera se han podido asimilar de nuestra civilización ni uno solo de sus conceptos»²1.

En mi opinión la idea de «Hermandad» hispano-marroquí remitía a un proyecto, en su sentido último no tan distinto a la voluntad "asimilacionista" (con sus propias limitaciones) que desplegó el colonialismo francés en el norte de África.

Pero, ciertamente, en autores como Costa, este tipo de argumentaciones sobre el parentesco, plantea interesantes ambivalencias. Susan MartínMarquez ha planteado una reflexión sobre las ambivalencias identitarias que la voluntad de dominio del norte de África generó en un país que a su vez había sido «orientalizado» [Martín-Márquez 2008, 57-63]. Esta autora tiende, sin embargo, a considerar tal ambivalencia como prueba de debilidad identitaria. En mi opinión, fue más bien la prueba de un intenso proceso de negociación, que arranca en el estereotipo ilustrado y romántico de España, pero que concluye con una poderosa afirmación esencialista de ser una nación europea [Andreu 2009].

En realidad todo ello abrió la puerta hacia la importancia de la «autoexotización» de las representaciones sobre la identidad española, en lo que fue un modelo tal vez singular respecto de otros países europeos. Dándole la vuelta a la imagen negativa del país "orientalizado» que sería España, esta imagen sería asumida para convertirla en palanca

20 También en Francia se desarrolló una teorización sobre el África latina, sobre el pasado romano en Argelia que habría sido interrumpido por la dominación musulmana. Véase: Ruscio 2002, 117-118. Este pasado histórico romano fue también uno de los puntales del colonialismo italiano en el norte de África.

21 Yáñez, 1910, 7-9. 
de autoafirmación, mediante el desvío hacia una supremacía espiritual (algo nada extraño a lo que efectuaron países sometidos al colonialismo en sus procesos de descolonización [Chtarajee 1993], aunque sí para países imperialistas) o "estética». Sin duda, el predominio del estereotipo andaluz-orientalista como imagen finalmente metonímica de «lo español» alcanzó en el fin de siglo un nuevo ímpetu, y un extraordinario eco internacional (que culminaría en la «españolada» como subgénero artístico) ${ }^{22}$. Probablemente, esta imagen facilitó (al reforzar el tópico ya existente) su aceptación y difusión, aunque tal vez no en el sentido deseado.

En 1884, Gumersindo de Azcárate, uno de los intelectuales más destacados de la Restauración, había reafirmado la idea de la "misión» de España en África. Apelando al pasado, a la historia, como había hecho dos años antes Cánovas, afirmaba que: «el corazón me dice que España, que sin duda alguna ha sido en lo pasado la primera nación colonizadora no puede renunciar a serlo, si no hoy, algún día, ya que esta misión está de acuerdo con su vocación, con sus aptitudes y con su historia». Pero, advertía: "Todos estamos conformes en que esa misión tiene España, pero no la ha de cumplir por medio de la guerra y menos buscar esta sin necesidad u olvidando que sólo en esos casos excepcionales es lícito intentar lo que no puede realizarse». La conclusión del argumento, desde luego, era que «Por consiguiente, si han de ser medios pacíficos los que debe emplear España en la misión que tiene respecto a Marruecos ¿cuáles son estos? No pueden ser más que dos: la cultura y el comercio» ${ }^{23}$. En efecto, la "penetración pacífica» propugnada desde los años ochenta era eso: una tarea de «civilización»². El argumento

22 Un ejemplo paradigmático es el de los pabellones neoarabes en las Exposiciones Universales de 1878 y 1900. Véase: Bueno Fidel 1987.

23 De Azcarate 1884, 50-51.

24 La argumentación se repetía incluso en aquellos autores más descarnadamente defensores de la dimensión económica de la presencia en Marruecos. Por ejemplo véase: De Reparaz, 1907. 
se repetiría insistentemente en los años siguientes, convertido en leit motiv $^{25}$.

Era el mismo tropo que la mayoría de los imperialismos europeos defendían, en definitiva, y no menos ambiguo en su objetivo final para el caso español que para otros ${ }^{26}$. Francisco Javier Martínez Antonio ha argumentado que la dimensión de «regeneración» que tomó el africanismo lo convertiría en una singularidad respecto a las tareas colonizadoras o de penetración pacífica al estilo francés o británico [Martínez Antonio 2011]. Pero tal vez la comparación con estos casos, especialmente el británico, explique la percepción de cierta singularidad del caso español, que tal vez se mitigaría al compararlo con Italia o Alemania, en ambos casos países que ansiaban el imperio como instrumento de supervivencia, como anteriormente hemos señalado. En segundo lugar, es verdad que el énfasis regeneracionista es casi desesperado en España, pero el discurso sobre Argelia del imperialismo francés no es tan diferente, en la convicción de lo positivo de un desarrollo a dos bandas. En tercer lugar, la idea regeneracionista no fue incompatible, antes al contrario con la tarea "civilizadora» ni modificó la representación del «otro». En realidad los materiales culturales dedicados a este fin (que desbordan al africanismo regeneracionista inspirado en Costa) son equiparables, en gran medida a los de cualquier otro país europeo. En este sentido, si bien no es posible intentar equiparar el «orientalismo» español con el británico o francés, tal vez puede hacerse con casos como el de la tradición germana, donde con o sin imperio, sirvió para luchar contra la subordinación cultural y política, y acentuar la pertenencia a la moderna civilización europea. De hecho, como ha señalado Todd Kontje la participación germana en los proyectos orientalistas

25 Ovilo, 1888, 39.

26 Sobre los equívocos que siempre rodearon la finalidad última (supuestamente la «asimilación» de los pueblos colonizados) del imperialismo francés, véase Girardet, 2007, 297-299. 
sirvió como compensación ante la incapacidad de ser un actor real en la escena internacional [Kontje 2004] ${ }^{27}$. Desde el ámbito académico, y por modesto que pudiera ser su alcance, desde la segunda mitad del siglo XIX está fuera de dudas se trazó un "otro» oriental no español [Rivière 2000, Morales Lezcano 1990]. Pero más importante fue, sin duda, el ámbito de las artes plásticas, de la pintura a la música (y en otro sentido, la arquitectura).

Por otra parte, es mucho más que anecdótico que los españoles se mostraron, en Marruecos o en cualquier otro marco "oriental» tan orientalistas y tan convencidos de representar la civilización occidental como cualesquiera otros europeos. Sirvan como ejemplo los testimonios escritos de los viajeros españoles por tierras «exóticas», esto es por Oriente (y por tanto más allá de sus propias posesiones coloniales [Litvak 1987 Córdoba, Pérez Díe 2006]) o por Marruecos [Marín 2015] ${ }^{28}$. Los viajeros españoles cumplieron la misma función que los de cualquier otro país europeo: construir una imagen de lo no europeo para consumo interno, nacional [Pratt 2008].

Hacia Marruecos se desplegará, en definitiva, un discurso civilizador, basado en el convencimiento eurocéntrico de la superioridad propia, no exenta de compasión o incluso simpatía, pero inevitablemente marcado por los límites de la alteridad. La tarea "civilizadora» parecía apuntar al convencimiento de la perfectibilidad de los pueblos norteafricanos ${ }^{29}$. La duda está en si el exceso de visión «orientalista» y su exotización no planteaba un límite infranqueable a la posibilidad de desarrollo, un reforzamiento de esta insondable alteridad ${ }^{30}$. En este sentido, cabe

\section{Para una perspectiva más escéptica, véase: Marchand 2009.}

28 Por cierto que la visión de los hombres viajeros no es demasiado diferente a las mujeres viajeras. Véase: Cerarols, 2009.

29 Algo no muy distinto a lo que planteaba el discurso colonialista racial francés. Véase: Reynaud-Paligot, 2008, 235.

$30 \mathrm{La}$ idea de los pueblos norteafricanos como «misteriosos» fue la imagen predominante en el caso francés y a pesar de la voluntad de asimilación del territorio argelino el exotismo 
plantearse, como antes señalaba si la idea de la «Hermandad» (e incluso la de la supuesta identidad racial «libio-íbera») fueron definitivamente anomalías del caso español. En primer lugar porqué estuvieron tan socavadas por la construcción efectiva por parte española de la alteridad marroquí que parecen no haber jugado el papel que teóricamente les correspondía. En segundo lugar porque tal vez no fueran mucho más allá de servir como cobertura cultural de la «misión civilizadora» y fueran a la postre equiparables a la voluntad de «asimiliación» (finalmente derivada en «asociación»y al final pura segregación) del colonialismo francés [Saada 2007].

Parece imposible, por tanto, menospreciar que el proyecto colonial desarrolló una imagen del «otro», del norteafricano (el «moro»), negativa y con tintes racistas [Mateo Dieste 1998] ${ }^{31}$. Se ha argumentado que una de las causas de debilidad del nacionalismo español fue la ausencia de un «otro», especialmente vinculado a conflictos bélicos, que diera cohesión a la identidad nacional. Sin embargo, Marruecos pudo jugar en el imaginario del nacionalismo español esta función [Martín Corrales 2012]. Es cierto que el sentido de las guerras de África y la imagen del «moro» atrasado no fueron equivalentes al significado de conflictos como el la Primera Guerra Mundial en Europa. Pero, el fracaso del proyecto colonial no implicó que no triunfara el reforzamiento de una concepción nacional española abiertamente opuesta a la imagen del magrebí.

\section{Epílogo}

La dimensión imperial del proyecto nacionalista español fue inseparable desde antes incluso de la crisis colonial de 1898, y claramente con el 
impulso regeneracionista, de la reflexión sobre una identidad nacional concebida permanentemente en crisis. Una crisis que el dictum de Lord Salisbury situó decididamente en un contexto de crisis postimperial.

Fue haciendo de la necesidad virtud, entre el reconocimiento de la falta de medios y el convencimiento moral, como se definió la voluntad imperial española32. En la práctica, cuanto más fracasó el proyecto colonial en sentido estricto, más se reforzó, como ya señalara J. L Mateo, la visión del proyecto civilizador como visión compensatoria. Por ello, la dimensión cultural debe situarse en el centro del análisis de los imaginarios del imperialismo español y perduró más allá de los fracasos. Algo que probablemente no sea una peculiaridad española, pues en palabras de Giuseppe Finaldi: «It appears ever more clear that Italy's 'culture of colonialism' must be primarly interpreted as a vital aspect of its nationbuilding Project. In one sense, the colonies themselves did not particularly matter» [Finaldi 2009, 298]. Al menos es una hipótesis que cabe explorar, también para el caso español.

El autor participa en el Proyecto HAR2014-53042-P del Ministerio de Economía y Competitividad de España.

\section{Bibliografía}

Akmir Y. 2009, De Algeciras a Tetuán, 1875-1906. Orígenes del proyecto colonialista en Marruecos, Rabat: Instituto de estudios Hispano-lusos.

Aldrich R. 2006, Vestiges of the colonial empire en France. Monuments, Museums, and colonial memories, London-New York: Palgrave.

Álvarez Chillida G., Martín Corrales E. 2013, Haciendo patria en África. España en 
marruecos y en el golfo de Guinea, en Moreno Luzón J., Núñez Seixas X. M. (eds.) 2013, Ser españoles. Imaginarios nacionalistas en el siglo XX, Barcelona: RBA editores: 399-432.

Andrade V. 2006, Traumas do Império. História, Memória e Identidade Nacional, «Cuadernos de Estudos Africanos», 9 (19): 23-41.

Andreu X. 2009, ${ }_{j}$ Cosas de Españaj Nación liberal y estereotipo romántico de España a mediados del siglo XIX, "Alcores», (7): 39-61.

Antón Ferrándiz M. 1895, Razas y naciones de Europa, Madrid: Imprenta colonial.

- 1910, Los orígenes étnicos de las nacionalidades libio-ibéricas, Madrid: Imprenta de Eduardo Arias.

Archilés F. 2011, Melancólico bucle. Narrativas de la nación fracasada e historiografía española contemporánea, en Saz I., Archilés F. (eds.) 2011, Estudios sobre nacionalismo y nación en la España contemporánea, Zaragoza: Publicaciones de la Universidad de Zaragoza, 245-330.

- 2012, Piel moruna, piel imperial. Imperialismo, nación y género en la España de la Restauración (c.1880-c.1909), "Mélanges de la casa de Velázquez», 42 (2): 37-54.

- 2013, ¿Ni imperio ni imperialismo? El imaginario nacional español y el imperialismo africanista en la España de la Restauración, en Archilés F., García M., Saz I. (eds.) 2013, Nación y nacionalización. Una perspectiva europea comparada, Valencia: Universitat de valencia, 201-224.

Aubert P. 2006, L'écriture du désastre: discourse sous la décadence et projects de régénération nationale en Espagne (1890-1914), en Aubert P. (ed.), Crise espagnole et renouveau idéologique et culturelen Mediterranée, Aix-en-Provence: Publications de l'Université de Provence: 201-232

Bachoud A. 1988, Los españoles ante las campañas de Marruecos, Madrid: Espasa-Calpe.

Balfour S. 2002, Abrazo Mortal. De la guerra colonial a la Guerra Civil en España y Marruecos (1909-1939), Barcelona: Ediciones Península.

Bancel N., Blanchard P., Vergés F. 2003, La république colonial, Paris: Hachette, Paris.

Baycroft T. 2004, The Empire and the Nation: the Place of Colonial Images in the Republican Visions of the French Nation, en Evans M. (ed.) 2004, Empire and Culture. The French Experience, 1830-1940, Basingstoke: Palgrave: 148-160.

Becker J. 1913, La Tradición colonial española, Madrid: Imprenta del Patronato de Huérfanos de Intendencia e Intervenciones Militares.

Bell D. 2007, The Idea of Greater Britain. Empire and the Future of World Order, 18601900, Princeton: Princeton University Press.

Blanco A. 2012, Cultura y conciencia imperial en la España del siglo XIX, Valencia: Publicaciones de la Universitat de Valencia.

Bueno Fidel M. J. 1987, Arquitectura y nacionalismo (pabellones españoles en las Ex- 
posicionoes universales del siglo XIX), Málaga: Universidad de Málaga-Colegio de Arquitectos.

Canovas A. 1883, Discurso sobre la nación, en Canovas A., Discurso sobre la nación, Madrid: Biblioteca nueva, 1997.

Cañete Jiménez C. 2009, El orígen africano de los íberos. Una perspectiva historiográfica, Tesis Doctoral, Málaga: Universidad de Málaga.

Chatarjee P. 1993, The Nation and its Fragments, Princeton: Princeton University Press.

Cerarols R. 2009, Viajeras españolas en Marruecos, Almeria: Instituto de estudios almerienses.

Conrad S. 2010, Globalisation and The Nation in Imperial Germany, Cambridge: Cambridge University Press.

- 2011, German Colonialism: a Short History, Cambridge-New York: Cambridge University Press.

Constantini D. 2008, Mission civilisatrice. Le rôle de l'histoire coloniale dans la construction de l'identité politique française, Paris: La découverte.

Cooper F., Stoler A-L. (eds.) 2007, Tensions of Empire. Colonial Cultures in a Bourgeois World, Berkeley: University of California Press.

Coquery-Vidrovitch C. 2009, Enjeux politiques de l'histoire coloniale, Paris: Agone.

Córdoba J. M., Pérez Díe M. C. (eds.) 2006, La aventura española en Oriente (11662006), Madrid: Ministerio de Cultura.

Costa J. 1883, El porvenir de la raza española, en Costa J. 1981 Reconstitución y europeización de España y otros escritos, Madrid: IEAL, 43-88.

- 1884, Discurso de Joaquín Costa en Coello F. 1951, Intereses de España en Marruecos, Madrid: Instituto de Estudios Africanos, 50-57.

De Azcárate G. 1884, Discurso del señor Azcárate, en Coello F. 1951, Intereses de España en Marruecos, Madrid: Instituto de Estudios Africanos et alii, Intereses de España en Marruecos, 60-67.

De Felipe H. 2005, Spain in Morocco in the 19th and 20th century: providentiality and colonization, "The Maghreb review», 30 (2-4): 198-208.

De Reparaz G. 1907, Política de España en África, Barcelona: Imprenta Barcelonesa.

Domingo Acebrón M. D. 2006, Rafael María de Labra. Cuba, Puerto Rico, las Filipinas, Europa y Marruecos, en la España del sexenio democrático y la Restauración, Madrid: CSIC.

Eley G. 2010, Imperial Imaginary, Colonial Effect: Writing the Colony and the Metropole Together, en Hall C., McLelland K. (eds.) 2010, Race, Nation and Empire. Making Histories, 1750 to the Present, Manchester: Manchester University Press, 217-236. 
Elizalde M. D. 1992, España en el Pacífico del siglo XIX: La colonia de las Carolinas, un modelo colonial en el contexto internacional del imperialismo, Madrid: CSIC.

Finaldi G. M. 2009, Italy's African Wars in the Era of Nation-Building, 1870-1900, Berna: Peter Lang.

Fradera J. M. 2005, Colonias para después de un Imperio, Barcelona: Edicions Bellaterra.

- 2006, Las fronteras de la nación y el ocaso de la expansión hispánica, en Pan-Montojo J. (de.) 2006, Más se perdió en Cuba, 1898 y la crisis del fin de siglo, Madrid: Alianza editorial: 483-557.

Frétigné J-Y., Jankowiak F. (eds.) 2008, La décadence dans la culture et la pensée politiques. Espagne, France et Italie, Roma: École française de Rome.

Gajate Bajo M. 2012, Las campañas de Marruecos y la opinión pública. El ejemplo de Salamanca y su prensa (1906-1927), Madrid: IUGGM-UNED.

García Balañá A. 2002, Patria, plebe y política en la españa isabelina: la guerra de África en Cataluña (1859-1860), en Martín Corrales E. M. (ed.) 2002, Marruecos y el colonialismo español (1859-1912). De la Guerra de África a la 'penetración pacífica', Barcelona: Bellaterra, 13-78.

- 2012, 'The Empire Is No Longer a Social Unit'. Declining Imperial Expectations and Transatlantic Crises in Metropolitan Spain (1859-1909) en McCoy A., Fradera J. M., Jacobson S. (eds.) 2012, Endless Empire. Spain's Retreat, Europe's Eclipse, American Decline, Maddison: University of Wisconsin Press, 92-106.

Gikandi S. 1996, Maps of Englishness. Writing Identity in the Culture of Colonialism, Nueva York: Columbia University Press.

Gil Grimau R. 1988, Aproximación a una bibliografía española sobre el norte de África, 1850-1980 I, Madrid: Dirección General de Relaciones Culturales.

Girardet R. 2007, L'idée coloniale en France de 1871 à 1962, Paris: Hachette.

González Alcantud A, Martín Corrales E. (eds.) 2007, La conferencia de Algeciras en 1906: un banquete colonial, Barcelona: Edicions Bellaterra.

Goode J. 2009, Impurity of Blood. Defining Race in Spain, 1870-1930, Baton Rouge: Louisiana University Press.

Hale D. S. 2006, Races on Display. French Representations of Colonized Peoples, 18861940, Bloomington: Indiana University Press.

Hall C., Rose S. (eds.) 2006, At Home with the Empire. Metropolitan Culture and the Imperial World, Cambridge: Cambridge University Press.

Hill C. L. 2008, National History and the World of Nations. Capital, State, and the Rethoric of History in Japan, France and the United States, Durham: Duke University Press, Durham.

Jacobsen S. 2012, Imperial Ambitions in an Era of Decline, en McCoy A., Fradera J. M., Jacobson S. (eds.) 2012, Endless Empire. Spain's Retreat, Europe's Eclipse, American 
Decline, Maddison: University of Wisconsin Press, 74-91.

Jefferies M. 2008, Contesting the German Empire, 1871-1918, Oxford: Blackwell.

Kontje T. 2004, German Orientalisms, Ann Arbor: The University of Michigan Press.

Labanca N. 2007, Oltremare. Storia dell' espansione coloniale italiana, Bologna: Il Mulino.

La Porte P. 1996, La respuesta urbana ante la crisis de Annual (1921-1923), "Revista de Estudios africanos», 18-19: 109-124

Le Cour Grandmaison O. 2009, La République Imperiale. Politique et racisme d'État, Paris: Fayard.

Lejeune D. 1993, Les societés de géographie en France et l'expansion coloniale au XIXè siècle, Paris: Albin Michel.

Litvak L. 1987, El ajedrez de las estrellas. Crónicas de viajeros españoles del siglo XIX por países exóticos (1800-1913), Barcelona: Laia.

Lorin A., Taraud, C. (dirs.) 2013, Nouvelle histoire des colonisations européenes XIXeXXe siècles. Societés, Cultures, politiques, Paris: Presses Universitaires de France.

MacKenzie J. M. 2008, 'Comfort' and Conviction: a Response to Bernard Porter, "The Journal of Imperial and Commonwealth History», 36 (4): 659-668.

- (ed.) 2011, European Empires and the People. Popular Responses to Imperialism in France, Britain, the Netherlands, Belgium, Germany and Italy, Manchester: Manchester University Press.

Mainer J. C. 1988, Un capítulo regeneracionista: el hispanoamericanismo (1892-1923), en Mainer 1988, La doma de la quimera (Ensayos sobre nacionalismo y cultura en España), Barcelona: Universitat de Barcelona, Barcelona, 87-138 .

Marchand S. L. 2009, German Orientalism in the Age of Empire, Cambridge: Cambridge University Press.

Marín M. 2015, Testigos coloniales: españoles en Marruecos [1860-1956], Barcelona: Edicions Bellaterra.

Martín Corrales E. 2002, La imagen del magrebi en España. Una perspectiva histórica, siglos XVI-XX, Barcelona Edicions Bellaterra.

- 2012, El 'moro' decano de los enemigos exteriores de España: una larga enemistad (siglos VIII-XXI), en Núñez Seixas X. M., Sevillano F. (eds.) 2012, Los enemigos de España. Imagen del otro, conflictos bélicos y disputas nacionales (siglos XVI-XX), Madrid: Centro de Estudios Políticos y Constitucionales, 165-182.

Marcilhacy D. 2010, Raza hispana: hispanoamericanismo e imaginario nacional en la España de la Restauración, Madrid: Centro de Estudios Políticos y Constitucionales.

Martínez Antonio F. J. 2011, "Dos dedos de una misma mano": propuestas para un nuevo análisis de las relaciones entre España y Marruecos a finales del siglo XIX, en Martínez Antonio F. J., González González I. (eds.) 2011, Regenerar España y Marruecos. Cien- 
cia y educación en las relaciones hispano-marroquies a finales del siglo XIX, Madrid: CSIC, 19-58.

Martín-Márquez S. 2008, Disorientations. Spanish Colonialism in Africa and the Perfomance of Identity, New Haven: Yale University Press.

Mateo Dieste J. L. 1998, El «moro» entre los primitivos. El caso del protectorado español en Marruecos, Barcelona: Edicions Bellaterra.

- 2003, La 'hermandad' hispano-marroquí. Política y religión bajo el Protectorado español en Marruecos (1912-1956), Barcelona: Edicions Bellaterra.

Monina G. 2002, Il consenso coloniale. La società geografiche e l'Instituto Coloniale italiano (1896-1914), Roma: Carocci.

Morales Lezcano V. 1990, El Norte de África, estrella del orientalismo español, "Awraq", XI: 17-34.

- 2002, El colonialismo hispano-francés en Marruecos (1898-1927), Granada: Universidad de Granada.

Morales Moya A., Fusi J. P., De Blas Guerrero A. 2013, Historia de la nación y del nacionalismo español, Barcelona: Galaxia Gutenberg.

Muñoz I. 1913, En el país de los cherifes, Madrid: Imprenta Helénica.

Natili D. 2008, Un programma coloniale, Roma: Gangemi.

Nogué J., Villanova J. L. 1999, Las sociedades geográficas y otras asociaciones en la acción colonial española en Marruecos, en Nogué J., Villanova J. L. (eds.) 1999, España en Marruecos (1912-1956), Lleida: Milenio, 183-224.

Ovilo F. 1888, Estado actual de Marruecos, Madrid: Librería de Fernando Fé.

Pedraz A. 2000, Quimeras de África. La Sociedad Española de Africanistas y Colonialistas. El colonialismo español de finales del siglo XIX, Madrid: Polifemo.

Pinto Coelho M. T. 1996, Apocalipse e regeneraçao: O ultimatum e a mitologia da Pàtria na literatura finisecular, Lisboa: Ediçoes Cosmos.

Porter B. 2004, The Absent-Minded Imperialists. Empire, Society and Culture in Britain, Oxford: Oxford University Press.

- 2008, Further Thoughts on Imperial Absent-Mindedness, «The Journal of Imperial and Commonwealth History», 36 (1): 101-117.

Pratt M. L. 2008, Imperial eyes. Travel Writing and Transculturation, London: Routledge.

Reynaud-Paligot C. 2008: La République raciale, 1860-1930, Paris: presses Universitaires de France.

Riviére A. 2000, Orientalismo y nacionalismo español: estudios árabes y hebreos en la Universidad de Madrid (1843-1868), Madrid: Dykinson.

Rodríguez Esteban J. A. 1996, Geografía y colonialismo. La Sociedad Geográfica de Ma- 
drid (1876-1936), Madrid: Universidad Autónoma de Madrid.

Ruscio A. 2002, Le Credo de l'homme Blanc, Bruselas: Complexe.

Saada E. 2007, Les enfants de la colonie. Les métis de l'Empire français, entre sujetion et citoyenneté, Paris: La Découverte.

Schivelbusch W. 2001, The Culture of Defeat. On National Trauma, Mourning and Recovery, New York: Metropolitan Books.

Schmidt-Nowara C. 2006, The Conquest of History. Spanish Colonialism and the National Histories in the Nineteenth Century, Pittsburgh: University of Pittsburgh Press.

Short J. P. 2012, Magic Lantern Empire, Colonialism and Society in Germany, Ithaca: Cornell.

Sibeud E. 2013, Cultures coloniales et impériales, en Singaravélou P. (dir.) 2013, Les empires coloniaux (XIXe-XXe siècle), Paris: Seuil.

Singaravélou P. 2011, Professer l'Empire. Les "sciences coloniales" en France sous la IIIe République, Paris: Publications de la Sorbonne.

Sobral J. M. 2004, O Norte, o Sul, a raça, a nação - representações da identidade nacional portuguesa (séculos XIX-XX), «Analise Social», XXX (171): 225-284.

Sluga G. 2006, The Nation, Psicology and International Politics, Basingstoke: Palgrave.

Thiesse A-M 2010, Faire les Français. Quelle identité nationale?, Paris: Stock.

Thompson A. 2005, The Empire strickes back? The Impact of Imperialism on Britain from the Mid-Nineteenth Century, Harlow: Longman.

Yáñez I. 1910, Marruecos. Estudios sobre el mismo con destino a las escuelas de $1^{a}$ enseñan$z a$, Burgos: Hijos de Santiago Rodríguez. 